\title{
Assessing the caring behaviors of critical care nurses
}

\author{
Samah Anwar Shalaby*1, Nouf Fahad Janbi ${ }^{2}$, Khairiah Khalid Mohammed ${ }^{2}$, Kholud Mohammed Al-harthi ${ }^{2}$ \\ ${ }^{1}$ Faculty of Nursing, Edmon Fremon St. Smouha, Alexandria, Egypt \\ ${ }^{2}$ College of Nursing, King Saud Bin Abdul-Aziz University for Health Sciences, Saudi Arabia
}

Received: February 21, 2018

DOI: $10.5430 /$ jnep.v8n10p77

\author{
Accepted: May 9, 2018 \\ Online Published: May 21, 2018 \\ URL: https://doi.org/10.5430/jnep.v8n10p77
}

\begin{abstract}
Objective: To assess the critical care nurses' perception of their caring behaviors and factors affecting these behaviors. Methods: Participants of this descriptive correlational exploratory study included 277 critical care nurses selected conveniently from nurses worked in all critical care units in King Khalid Hospital, Jeddah. A self-reported questionnaire namely, "Critical Care Nurses Caring Behavior Perception" developed by the researchers after reviewing related literature was used to assess caring behaviors and their affecting factors as perceived by critical care nurses.

Results: Seventy percent of the nurses aged between 31 to 50 years old and more than half of nurses had ICU experience ranged from 6 to 10 years, while two thirds of nurses had no previous training about caring behaviors. The study findings revealed that the majority of nurses had high scores of perceived caring behaviors, whereas the mean of their perception was $296.96 \pm 18.32$. There was a statistical significant positive relationship between nurses' perception and their work circumstances, workload, job satisfaction, educational background and patient characteristics.

Conclusions: It is important to consider critical units' circumstances, nurses' educational background, job satisfaction, as well as the nature of critically ill patients in order to promote nurses awareness and implementation of caring behaviors. Moreover, replication of the current study using qualitative approach for in-depth analysis of the impact of factors could affecting caring behaviors on nurses' perception in various highly specialized critical care units.
\end{abstract}

Key Words: Critical care nurse, Caring behavior, Perception, Job satisfaction

\section{INTRODUCTION}

Caring has been described as the moral ideal of nursing and the 'heart' of nursing. ${ }^{[1]}$ Moreover, caring is the major intellectual, theoretical, heuristic, and core central to the practice of the nursing profession. ${ }^{[2,3]}$ Despite the lack of a universal definition for caring, it is known that in consist of two major elements of instrumental and expressive actions. The instrumental caring behaviors consist of the technical and physical behaviors, and the expressive caring behaviors include the psychosocial and emotional behaviors. ${ }^{[4]}$ The caring behaviors include a wide variety of features and actions and these may be words, thoughts, feelings, looks, actions, movement, gestures, body language, touch, acts, procedures and/or information. ${ }^{[5]}$ Therefore, caring entails personal, spiritual, moral and to a certain degree the social involvement of the nurse, as they commit to self, health team members and patients. ${ }^{[6]}$

Watson (2009) theory shows that caring as the disciplinary foundation for nursing and caring science as an advanced view of nursing and human sciences. ${ }^{[7]}$ Watson articulated ten carative factors which conceptually and practically illustrate caring behaviors and these encompassed; formatting a humanistic-altruistic system of values, strengthening hope

\footnotetext{
*Correspondence: Samah Anwar Shalaby; Email: samahanwar1 @ gmail.com; Address: Faculty of Nursing, Edmon Fremon St. Smouha, 21527, Alexandria, Egypt.
}

Published by Sciedu Press 
and faith, cultivating self and/or others sensitivity, establishing a help-trust relationship, encouraging and accepting both positive and negative feelings expression, and utilizing a creative problem-solving caring process. The other factors articulated by Watson were providing a transpersonal teachinglearning, providing protective, corrective and/or supportive physical, social, spiritual, and mental environment, enhancing the gratification of human needs, and existentialphenomenological-spiritual forces. ${ }^{[7,8]}$

In nursing practice the nurses' caring behaviors may be influenced by numerous factors and these may include the patient's diagnosis, the type of institution, nurse's age and experience, self-respect, beliefs and workplace circumstances. ${ }^{[9,10]}$ Literature also shows that there are cultural differences in caring behaviors. ${ }^{[11]}$ Other studies have reported that the methods used in nurse's assignment, lack of time and lack of caring support can significantly impact nurses' caring behaviors. ${ }^{[12,13]}$

Critical care nurses have a crucial role in providing direct individualized holistic care to meet the bio-psycho-social needs of critically ill patients and their families via the integration of caring processes. Available studies focusing on caring-oriented behaviors in critical care settings have described how critical nurses care for patients and their families. ${ }^{[14,15]}$ However critical care nurses continue to be confronted with critically ill patients' in pain, agony, facing difficulty life support decisions and complicated therapeutic modalities. ${ }^{[16]}$ Critical care nurses regularly face challenging ethical dilemmas associated with patients' care, advanced technology and tremendous changes in healthcare delivery, all of which necessitate the implementation of challenging decisions and new advocacy and caregiver responsibilities for the nurses. ${ }^{[17]}$

Nurses may be confronted with barriers in their ability to express caring in the critical care settings. The barriers can result into limited caring time for the patients and limited expression of caring behaviors, hence a difficulty in finding meaning or value in nurses' work and subsequently a decline in job satisfaction. ${ }^{[18]}$ The critical care units are usually considered to be highly stressful environments for the patients, their families and the health care providers. The stress in the critical care settings is extended by regular activities such as difficult decisions related to end-of-life care, strict standards for quality of patient care, inadequate opportunities for communication with relatives and high ICU nurse's turnover rates. ${ }^{[19]}$ The use of advanced technology has also tremendously limited the opportunities for improving caring communication, caring involvement, and caring provision in a safe effective and time saving manner. ${ }^{[20]}$
Thus, nurses in a high technology environment may need more emphasis on advocacy roles and direct patients care. ${ }^{[21]}$ Critical care nurses should maintain the balance between their technological and humanistic caring behaviors during the provision of individualized holistic patient care. ${ }^{[22]}$ The other factors influencing critical care nurses' caring behaviors include the nurse-patient ratio because this is critical to the establishment of a therapeutic nurse-patient relationship and helps the nurses to incorporate caring behaviors into comprehensive patient care. ${ }^{[23,24]}$ The critical care nurses' work experience may also alter their caring behaviors and it has been reported to have a positive correlation to the nurse's caring behavior. ${ }^{[25-28]}$

The patient factors may also influence the nurses' caring behaviors in critical care settings since in such settings nurses are dealing with patients who have life threatening health problems and dependent on advanced machines to support life as mechanical ventilators. Literature shows that experienced nurses caring for awaken mechanically ventilated patients find it to be more demanding but improved with good opportunities for patient interactions, and to incorporate patient needs and preferences. ${ }^{[29]}$

Critical care nurses are significant members of the health care team and work in a complex environment. Critical care nurses confront multiple factors and situations that need them to be aware of the need and role of caring behaviors. ${ }^{[30,31]}$ The current study was conducted to assess the critical care nurses perception of their caring behaviors and factors affecting these behaviors.

\section{Research questions}

What are the caring behaviors perceived by critical care nurses at King Khalid Hospital, Jeddah? Is there a relationship between the critical care nurses' characteristics and their caring behavior perception? What are the factors affecting critical care nurses' caring behaviors?

\section{Methodology}

\subsection{Design}

A descriptive correlational design was used in this study. The study was conducted at King Khalid Hospital (KKH) which is 531-beds military hospital located in the Western Region of Saudi Arabia. The study focused on all critical care units in $(\mathrm{KKH})$. The units where the data was collected were the following; four general intensive care units (ICU 1, ICU 2, ICU 3 and ICU 4), coronary care unit (CCU), acute coronary intensive care unit (ACICU), neonatal care unit (NICU), pediatric intensive care unit (PICU), burns care unit, and emergency department (ED). 


\subsection{Study participants}

A convenience sampling technique was used to recruit the participants from each of the above critical care units. The total number of nurses working in critical care units was 277 . The number of nurses working in the general ICUs, CCU, ACICU, NICU, Burns and emergency department was 58, 17, $25,56,16,17$ and 88, respectively. Regarding the inclusion criteria for participants, all critical care nurses in previously mentioned critical care units and willing to participate were included in the current study.

\subsection{Study instrument}

A self-administered questionnaire consisting of three parts was used for data collection. The first part of the questionnaire had items collecting data about the nurses' Demographic characteristics of age, gender, country of residence, educational level, past and current ICU work experience duration and setting/s, in addition to the current ICU environment. The second part of the questionnaire was the Modified version of Caring Behaviors Assessment Scale (CBAS). The CBAS is a standardized scale which was developed by Cronin and Harrison in 1988. The CBAS has 63 items categorized under 7 domains of caring behaviors based on Watson's carative factors as follows; humanism/faith-hope/sensitivity (16 items), helping/trust (11 items), positive/negative feelings expression (4 items), teaching/learning (8 items), supportive/protective/corrective environment (12 items), human needs assistance (9 items) and existential/phenomological/spiritual forces (3 items). Whereas, its reliability of the CBAS using Chronbach's alpha has been reported to range from 0.66 to 0.90 for the seven subscales. ${ }^{[17,32]}$ All items of the CBAS are rated on a 5-point Likert scale [1 for less important to 5 for most important]. The CBAS was slightly modified in the current study and the modifications included rephrasing of all 63 statements on the original tool so that each statement reflected the perception of the nurses and not that of the patients as indicated on original tool. The third section of questionnaire included the Factors of Nurses Caring Behaviors [FNCB] which was used to identify the factors perceived to affect the caring behaviors of critical care nurses. The FNCB was developed by the researcher after reviewing the related literature. ${ }^{[9,10,13]}$ The FNCB consisted of 32 items about the possible factors which may affect the nurses caring behaviors. The factors were categorized under four categories of: work place circumstances (14 items), nurses' workload, job satisfaction, and general interest in nursing profession (6 items), nurses' educational background (4 items), and patients' characteristics ( 8 items) All the items were rated on a 5-point Likert scale (1 for totally do not affect to 5 for completely affect). The questionnaire was tested for validity by asking the 5 experts in the field to assess relevancy and necessary modifications were done and after pilot the tool was tested. The Chronbach's alpha for modified CBAS and the FNCB were .96 and .93 respectively.

\subsection{Ethical considerations}

The study was reviewed and approved by the research and ethics committee of the college of nursing- Jeddah and KAIMRC. All the respondents were fully informed about the research purpose and the nature of the study. Also all respondents were required to indicate their willingness to participate in the study by signing a consent form. Participants were informed of their right to withdraw from the study at any time. The confidentiality of participants was mianatained by using code numbers rather than respondents' real names during data collection and analysis. The questionnaire used for data collection were handled only by the research team.

\subsection{Data analysis}

The data was analyzed using the Statistical package for social science software (SPSS version 20) software. Descriptive statistics were used to describe the sample and nurses' caring behaviors. The correlaton statistics, $t$-test, and ANOVA were used to evalaute relationships between perceived caring behaviors and demographic characteristics. The significance level was set at $p<.05$.

\section{Results}

\subsection{General description of socio-demographic and work related characteristics}

Table 1 shows the distribution of critical care nurses according to their socio-demographic and work related characteristics. The table revealed that the total number of nurses was 277. In relation to their age and gender, it was found that nurses' age ranged between 20 and 60 years old, whereas above two thirds of the studied sample $(70.8 \%)$ were in the age group between 31 to 50 years old and the majority of nurses $(87 \%)$ were females. In relation to marital status, the result demonstrates that more than half of the studied sample $(53.8 \%)$ was married.

Concerning the nurses' educational level, it was found that $63.9 \%$ of nurses had bachelor degree of nursing, while about one third of the nurses $(36.1 \%)$ had diploma degree. Regarding nurses' previous training or awareness about caring, around two thirds of nurses $(65.3 \%)$ had no previous caring training. 
Table 1. Distribution of nurses according to their characteristics

\begin{tabular}{|c|c|c|c|}
\hline Characteristic & Category & No. $(n=277)$ & $(\mathbf{1 0 0 \% )}$ \\
\hline \multirow{4}{*}{ Age in years } & $20-30$ & 12 & $4.3 \%$ \\
\hline & $31-40$ & 88 & $31.8 \%$ \\
\hline & $41-50$ & 108 & $39.0 \%$ \\
\hline & $51-60$ & 69 & $24.9 \%$ \\
\hline \multirow{2}{*}{ Gender } & Male & 36 & $13 \%$ \\
\hline & Female & 241 & $87 \%$ \\
\hline \multirow{3}{*}{ Marital status } & Single & 105 & $37.9 \%$ \\
\hline & Married & 149 & $53.8 \%$ \\
\hline & Divorced & 23 & $8.3 \%$ \\
\hline \multirow{2}{*}{ Level of professional education } & Diploma & 100 & $36.1 \%$ \\
\hline & Bachelor & 177 & $63.9 \%$ \\
\hline \multirow{2}{*}{ Received previous caring training } & No & 181 & $65.3 \%$ \\
\hline & Yes & 96 & $34.7 \%$ \\
\hline \multirow{4}{*}{ ICU Work experience in years } & $<1$ & 22 & $7.9 \%$ \\
\hline & $1-5$ & 50 & $18.1 \%$ \\
\hline & $6-10$ & 98 & $53.8 \%$ \\
\hline & $>10$ & 56 & $20.2 \%$ \\
\hline \multirow{7}{*}{ Unit of Work } & General ICU & 58 & $21 \%$ \\
\hline & $\mathrm{CCU}$ & 17 & $6.1 \%$ \\
\hline & ACICU & 25 & $9 \%$ \\
\hline & NICU & 56 & $20.2 \%$ \\
\hline & PICU & 16 & $5.8 \%$ \\
\hline & Burns & 17 & $6.1 \%$ \\
\hline & Emergency & 88 & $31.8 \%$ \\
\hline \multirow{3}{*}{ Current unit workload (nurse to patient ratio) } & $1: 1$ & 112 & $40.4 \%$ \\
\hline & $1: 2$ & 77 & $27.8 \%$ \\
\hline & $1: 4$ & 88 & $31.8 \%$ \\
\hline
\end{tabular}

Regarding to ICU experience duration, it was found that the majority of nurses $(71.9 \%)$ had more than one year up to ten years of experience, compared to only (7.9\%) had less than one year experience, while around one fifth of nurses (20.2\%) had more than10 years of ICU experience.

In relation to the current workplace, it was found that around one third of nurses $(31.8 \%)$ worked at emergency department (ER), one-fifth $(21 \%)$ of nurses worked in General ICU similar to the percentage of nurses who worked in NICU. While the lower percentage (less than 10\%) of nurses worked in each of other critical units included; CCU, ACICU, and PICU. Regarding the current unit workload, it was found that around two third of nurses (68.2\%) were assigned to one or two patients expect for ER nurses (31.8\%) were assigned to four patients.

\subsection{Perceived nurses caring behaviors}

Table 2 shows the mean score and standard deviation of the $\mathrm{NCBs}$ and related categories. (NCBs) scores ranged between 189 and 315 represented by mean score $(296.96 \pm 18.32)$.
The highest ranking of the NCBs categories was related to Human/ Needs assistance presented by $95.9 \%$ mean score percent and mean \pm SD $(43.16 \pm 2.99)$, followed by the environment presented by $95.2 \%$ mean score percent and mean $\pm \mathrm{SD}(57.12 \pm 3.67)$. While, the least reported NCBs category mean was related to Teaching/Learning presented by $92.1 \%$ mean score percent and mean \pm SD (36.86 \pm 3.86).

Regarding the mean score and standard deviation of the factors affecting NCBs and related categories, Factors affecting NCBs scores ranged between 54 and 160 represented by mean score $(134.72 \pm 20.8)$. The highest factor affecting NCBs was workload and job satisfaction represented by $90.2 \%$ mean score percent and mean $\pm \operatorname{SD}(27.05 \pm 4.90)$, followed by the workplace circumstances represented by $85.7 \%$ mean score percent and mean $\pm \mathrm{SD}(59.97 \pm 10.14)$. While, the least reported factor affecting NCBs was patient characteristics represented by $72.7 \%$ mean score percent and mean $\pm \mathrm{SD}(29.06 \pm 8.77)$. For additional information (see Table 2). 
Table 2. Description of nurses' perceived caring behaviors and affecting factors

\begin{tabular}{llllll}
\hline Item & Categories & Min & Max & Mean \pm SD & Ranking (\%) \\
\hline \multirow{4}{*}{ Caring } & Humanism/Faith/Hope & 48 & 80 & $75.19 \pm 5.09$ & 93.9 \\
Behaviors & Helping/Trust & 33 & 55 & $51.99 \pm 4.42$ & 94.5 \\
& Feelings expression & 12 & 20 & $18.61 \pm 1.96$ & 93.1 \\
& Teaching/Learning & 8 & 40 & $36.86 \pm 3.86$ & 92.1 \\
& Environment & 36 & 60 & $57.12 \pm 3.67$ & 95.2 \\
& Human/Needs Assistance & 27 & 45 & $43.16 \pm 2.99$ & 95.9 \\
Factors & Spiritual Forces & 8 & 15 & $14.04 \pm 1.43$ & 93.6 \\
affecting & Workplace circumstances & 28 & 70 & $59.97 \pm 10.14$ & 85.7 \\
& Workload/job satisfaction & 7 & 30 & $27.05 \pm 4.90$ & 90.2 \\
& Educational background & 11 & 20 & $16.71 \pm 2.07$ & 83.6 \\
\end{tabular}

Table 3 exhibits scores of the perceived importance of perceived NCBs, it reveals that the majority of nurses (96.8\%) perceived high importance level of caring behaviors. Whereas, only $3.2 \%$ of nurses perceived low importance of their caring behaviors.
Also it displays scores of the perceived effectiveness of factors affecting NCBs, the table reveals that the majority of nurses $(79.8 \%)$ perceived high effectiveness level of factors affecting NCBs. Whereas, only $20.2 \%$ of nurses perceived low effectiveness level of their factors affecting caring behaviors.

Table 3. Nurses perceived importance of caring behaviors and the effect of factors on their caring behaviors

\begin{tabular}{lllllll}
\hline Factor & Rating & No of nurses & Percent (\%) & Min & Max & Mean \pm SD \\
\hline \multirow{2}{*}{ Perceived NCBs scores } & Low important & 9 & 3.2 & 189 & 251 & $296.96 \pm 18.32$ \\
& High important & 268 & 96.8 & 252 & 315 & 127 \\
\multirow{2}{*}{ Factor affecting NCBs } & Low effective & 56 & 20.2 & 54 & $143.78 \pm 8.66$ \\
& High effective & 221 & 79.8 & 128 & 160 & \\
\hline
\end{tabular}

3.3 Relationship between nurses' characteristics and their perceived caring behaviors and affecting factors

Table 4 exhibits the relationship between NCBs and factors affecting $\mathrm{NCBs}$, it was found that there is a positive significant correlation between all categories of NCBs and factors affecting their caring behaviors whereas, $p$ significant at .05 level except for Helping/Trust relationship category of NCBs which has significant correlation only with educational background and workload/job satisfaction at .05 level.

Table 5 displays the relation between nurses' sociodemographic/work related characteristics with their perceived caring behaviors categories and factors affecting their caring behaviors. From this table it was seen that, there is no significant relationship between nurses caring behaviors with their age, gender, and marital status. On the other hand, a significant relationship was found between NCBs and their experience and workload where $p=.000$ for all caring categories. Also, there is a positive significant correlation between nurses previous training only with Helping/Trust, and Environment caring categories where $p=.031$ and .018 respectively. In addition, there is a positive significant correlation between nurses educational level only with feelings expression, Environment and Human/Needs assistance caring categories where $p=.023, .004$ and $p=.004$ respectively.

Regarding the factors affecting nurses' caring behaviors, it was found that, there is no significant relationship between factors affecting NCBs and nurses' age, marital status, and educational level. On the other hand, a significant relationship was found between factors affecting NCBs and nurses' experience and workload where $p=.000$ for all factors categories. Also, there are significant relationship between nurses' gender with work place circumstances and workload/ job satisfaction factors where $p=.004$ and .040 respectively. In addition, there is a positive significant correlation between nurses previous training with educational background, and workload/job satisfaction factors where $p=.041$ and $p=.047$ respectively. 
Table 4. Correlations between perceived nurses' caring behaviors (PNCBs) and factors affecting their caring behaviors

\begin{tabular}{|c|c|c|c|c|c|c|c|c|c|}
\hline \multirow[b]{2}{*}{$\begin{array}{l}\text { NCBs } \\
\text { Factors }\end{array}$} & & \multicolumn{8}{|c|}{ Perceived Nurses Caring Behaviors } \\
\hline & & $\begin{array}{l}\text { Humanism } \\
\text { Faith/Hope }\end{array}$ & $\begin{array}{l}\text { Helping } \\
\text { /trust }\end{array}$ & $\begin{array}{l}\text { Feelings } \\
\text { expression }\end{array}$ & $\begin{array}{l}\text { Teaching } \\
\text { Learning }\end{array}$ & Environment & $\begin{array}{l}\text { Human } \\
\text { Needs } \\
\text { Assistance } \\
\end{array}$ & $\begin{array}{l}\text { Spiritual } \\
\text { Forces }\end{array}$ & $\begin{array}{l}\text { Total } \\
\text { PNCBs }\end{array}$ \\
\hline \multirow{2}{*}{$\begin{array}{l}\text { Work place } \\
\text { circumstances }\end{array}$} & $r$ & .305 & .065 & .253 & .381 & .352 & .126 & .323 & .324 \\
\hline & $p$ & $.000 * *$ & .282 & $.000^{* *}$ & $.000 * *$ & $.000 * *$ & $.036^{*}$ & $.000^{* *}$ & $.000 * *$ \\
\hline \multirow{2}{*}{$\begin{array}{l}\text { Educational } \\
\text { background }\end{array}$} & $r$ & .433 & .449 & .407 & .286 & .517 & .251 & .409 & .509 \\
\hline & $p$ & $.000 * *$ & $.000 * *$ & $.000 * *$ & $.000 * *$ & $.000 * *$ & $.000 * *$ & $.000 * *$ & $.000 * *$ \\
\hline \multirow{2}{*}{$\begin{array}{l}\text { Patient } \\
\text { characteristics }\end{array}$} & $r$ & .211 & .028 & .164 & .300 & .198 & .119 & .270 & .226 \\
\hline & $p$ & $.000 * *$ & .648 & $.006^{* *}$ & $.000 * *$ & $.001 * *$ & $.049 *$ & $.000 * *$ & $.000 * *$ \\
\hline \multirow{2}{*}{$\begin{array}{l}\text { Workload/ job } \\
\text { satisfaction }\end{array}$} & $r$ & .226 & .122 & .191 & .339 & .234 & .307 & .258 & 0.302 \\
\hline & $p$ & $.000 * *$ & $.042 *$ & $.001^{* *}$ & $.000 * *$ & $.000^{* *}$ & $.000 * *$ & $.000^{* *}$ & $.000 * *$ \\
\hline
\end{tabular}

Note. $r$ : Pearson coefficient, ${ }^{*} p \leq .05$ at $5 \%$ level denotes a significant difference, ${ }^{* *} p \leq .01$ at $1 \%$ level denotes a highly significant difference.

Table 5. Relationship between demographic characteristics with nurses' perceived caring behaviors and the factors affecting their caring behaviors

\begin{tabular}{|c|c|c|c|c|c|c|c|c|}
\hline \multirow{4}{*}{ Item } & \multirow{4}{*}{ Categories } & \multicolumn{7}{|c|}{ Nurses' Characteristics } \\
\hline & & Age & Gender & $\begin{array}{l}\text { Marital } \\
\text { Status }\end{array}$ & $\begin{array}{l}\text { Education } \\
\text { level }\end{array}$ & $\begin{array}{l}\text { Previous } \\
\text { training }\end{array}$ & Experience & Workload \\
\hline & & $t$ & $t$ & $\mathbf{F}$ & $\mathbf{F}$ & $t$ & $\mathbf{F}$ & $\mathbf{F}$ \\
\hline & & $(p)$ & $(p)$ & $(p)$ & $(p)$ & $(p)$ & $(p)$ & $(p)$ \\
\hline \multirow{14}{*}{$\begin{array}{l}\text { Caring } \\
\text { Behaviors }\end{array}$} & Humanism/ & .003 & -.001 & 1.028 & 1.429 & -1.000 & 3.427 & 5.793 \\
\hline & Faith/Hope & .965 & .999 & .359 & .241 & .318 & $.001^{* *}$ & $.003^{* *}$ \\
\hline & Helping/ & .053 & 1.032 & 2.521 & 2.807 & -2.169 & 7.233 & 18.858 \\
\hline & Trust & .377 & .303 & .082 & .062 & $.031^{*}$ & $.000^{* *}$ & $.000^{* *}$ \\
\hline & Feelings & .057 & .289 & 1.845 & 3.814 & -1.869 & 5.226 & 12.497 \\
\hline & expression & .344 & .773 & .160 & $.023^{*}$ & .063 & $.000^{* *}$ & $.000^{* *}$ \\
\hline & Teaching/ & -.083 & -.644 & .163 & 1.751 & -.932 & 9.214 & 8.849 \\
\hline & Learning & .166 & .520 & .850 & .176 & .352 & $.000^{* *}$ & $.000^{* *}$ \\
\hline & \multirow{2}{*}{ Environment } & .050 & .862 & 1.033 & 5.743 & -2.379 & 9.394 & 28.463 \\
\hline & & .407 & .389 & .357 & $.004^{* *}$ & $.018^{*}$ & $.000^{* *}$ & $.000^{* *}$ \\
\hline & Human/Needs & .100 & .979 & 1.174 & 5.523 & -1.824 & 4.270 & 12.506 \\
\hline & Assistance & .098 & .329 & .311 & $.004^{* *}$ & .069 & $.000^{* *}$ & $.000^{* *}$ \\
\hline & \multirow{2}{*}{ Spiritual Forces } & .070 & 1.320 & 2.822 & .446 & -1.876 & 8.229 & 25.470 \\
\hline & & .245 & .188 & .061 & .641 & .062 & $.000^{* *}$ & $.000^{* *}$ \\
\hline \multirow{8}{*}{$\begin{array}{l}\text { Factors } \\
\text { affecting }\end{array}$} & Workplace & -.037 & 2.892 & .230 & .582 & -.864 & 16.570 & 9.256 \\
\hline & circumstance & .542 & $.004^{* *}$ & .795 & .559 & .388 & $.000^{* *}$ & $.000^{* *}$ \\
\hline & Educational & .021 & -.409 & 1.810 & .195 & -2.051 & 6.277 & 12.660 \\
\hline & background & .724 & .386 & .166 & .823 & $.041^{*}$ & $.000^{* *}$ & $.000^{* *}$ \\
\hline & Patient & -.054 & -.653 & .394 & .171 & -1.537 & 9.237 & 11.017 \\
\hline & characteristic & .366 & -.514 & .675 & .843 & .126 & $.000^{* *}$ & $.000^{* *}$ \\
\hline & Workload/job & -.082 & 2.060 & .323 & 2.290 & -1.998 & 18.877 & 17.028 \\
\hline & satisfaction & .174 & $.040^{*}$ & .725 & .103 & $.047^{*}$ & $.000^{* *}$ & $.000^{* *}$ \\
\hline
\end{tabular}

Note. $p$ value for nurse's $t$-test; Fp: $p$ value for F-test (analysis of variance [ANOVA]). ${ }^{*} p \leq .05$ at $5 \%$ level denotes a significant difference; $* * p \leq .01$ at $1 \%$ level denotes a highly significant difference.

\section{DiscuSSION}

Critical care nurses provide a comprehensive care to meet the bio-psycho-social needs of critically ill patients and their families. Therefore, the current study aimed to explore the critical care nurses perception of their caring behaviors as well as the factors affecting their caring behaviors, and pin- 
point the relationship between the nurses' perception and their socio-demographic and work related characteristics in King Khalid Hospital (KKH).

The current study findings revealed that the majority of nurses' age ranged between 31 to 50 years old which may be due to the hospital attitude to hire highly experienced nurses in the critical care units. Surprisingly, the majority of nurses had no previous training regarding caring behaviors in relation to their higher perception of caring behaviors, which can be as a result of hospital caring policy and attitude. Moreover, the current study findings revealed that the emergency nurses' workload was one to four because of high turnover rate in the nurse emergency department while the nurse patient ratio was one to one or two patients in other critical care units.

Apparently the majority of critical care nurses in $\mathrm{KKH}$ perceived their caring behaviors as highly important specifically human needs assistance which was rated by nurses as the first most important caring behaviors category which confirmed the significance of physiological aspect of care and assistance of critically ill patients for gratification of their physiological needs as the first priority based on Maslow hierarchy of human needs. Which is in line with other researchers who reported that human needs assistance category as the most important caring behaviors as perceived by nurses. ${ }^{[33,34]}$ Similarly to Pajnkihar et al. (2017) results which entitled the carative factor needs as the highest caring behaviors as perceived by nurses. ${ }^{[35]}$ This is contradicting with O'Connell and Landers (2008) who reported that the highest score of nurses caring behaviors was related to humanism/faith/hope/sensitivity domain of caring. ${ }^{[22]}$

Furthermore, the current study findings also revealed that the supportive/protective/corrective environment items ranked as the second highly important caring behaviors by nurses. This may be influenced by nurses' awareness with the vulnerability nature of the critically ill patients and the importance of maintaining patients' safety and protection in highly sophisticated, hostile and stressful ICU environment. ${ }^{[19,36]}$

On the other hand, the current study findings revealed that the Teaching/Learning items ranked as the least important caring behaviors by nurses. Which may be rationalized due to limitation in patients' communication by intubation, mechanical ventilation and alteration of patients' level of consciousness which are common problem within the critically ill patients society, ${ }^{[37]}$ in addition to low impact of the effect of the cognitive domain of care from the nurses' perspective, especially the majority of these nurses did not receive any previous training or awareness regarding the caring behaviors. This was incongruent with the findings of other authors who reported that the highest perceived nurses caring behaviors were related to Teaching/Learning on the cognitive domain of caring. ${ }^{[25]}$

Concerning factors affecting the critical care nurses caring behaviors, the current study findings entitled; workload and job satisfaction, workplace circumstances, educational background, as well as the nature of patients' characteristic, as the overall categorical factors that reported as highly effective on NCBs by eighty percent of nurses. Furthermore, all these factors encountered tremendous challenges for nurses and influence their perception of caring behaviors. ${ }^{[9]}$

Furthermore, the current research findings showed that the workload and job satisfaction was ranked by nurses as the first categorical factor affecting NCBs. This is congruence with Elbahnasawy et al. (2016) who found that above half of nurses reported that heavy workload act as a barrier against Watson theory application. ${ }^{[33]}$ Which is supported by other study findings which demonstrated that heavy workload by inadequate nurse-to-patient ratio was perceived as the greatest barriers to care provision. ${ }^{[13,30]}$ Furthermore, Salimi and Azimpour (2013) presented job satisfaction as the highest score affecting caring behavior. ${ }^{[9]}$

Moreover, the current study findings revealed no significant relationship between NCBs with their age, gender, and marital status. This is similar to another study about cancer nurses' perceptions of caring behaviors. ${ }^{[38]}$ While the current study found a positive correlation between nurses' previous training and workload/job satisfaction with their environment caring categories which is in line with Shen and coauthors' findings whereas nurses' quality of care was affected by the hospital environment. ${ }^{[39]}$ On the other hand, patients' characteristic was the least effective factor on NCBs as reported by nurses. This is in line with other study ${ }^{[9]}$ which reported the patients' gender and age represented by the lowest mean score among the factors affecting caring behaviors, which may be rationalized by the nurses' fair and equal approach in caring provision regardless the patients' characteristics and conditions.

\section{Conclusions}

The current study offered an evidence that the critical care nurses in $(\mathrm{KKH})$, Jeddah had high awareness regarding all categories of caring behaviors toward the critically ill patients include: humanism/faith/hope, and sensitivity, Helping/trust, expression of positive and negative feelings, teaching/learning, supportive/protective/corrective environment, human needs assistance in addition to existential/phenomological and spiritual forces. However, nurses highly emphasized on the importance of caring behaviors belong to human needs assistance and support- 
ive/protective/corrective environment categories of all caring behaviors, while teaching/learning did not have the same higher influence on nurses' perceptions of carative factors.

Differences in health care institutions probably, relate to different caring cultures and nurses' workload. Therefore, it is important to consider ICU circumstances, nurses' educational background, job satisfaction, as well as the nature of critically ill patients in order to promote nurses awareness and implementation of caring behaviors. Moreover, replication of the current study using qualitative design to pinpoint the differences in various hospital settings and correlate with a wide diversity of nurses' characteristics and caring cultures.

\section{ACKNOWLEDGEMENTS}

This study was supported by King Saud Bin Abdul-Aziz University, college of nursing research unit. The authors welling to acknowledge ICUs' nurses in King Khalid HospitalJeddah for their tremendous cooperation and support during this study.

\section{CONFlicts of InTEREST Disclosure}

The authors declared no conflicts of interest.

\section{REFERENCES}

[1] Watson J, Brewer B. Caring Science Research: Criteria, Evidence, and Measurement. JONA: The Journal of Nursing Administration. 2015; 45(5): 235-236. PMid:25906128 https://doi.org/10.1 097/NNA. 0000000000000190

[2] Moghaddasian S, Dizaji S, Mahmoudi M. Nurses Empathy and Family Needs in the Intensive Care Units. Journal of Caring Sciences. 2013; 2(3): 197-201. PMid:25276727

[3] Hardicre J. Nurses' experiences of caring for the relatives of patients in ICU. Nursing Times. 2003; 99(29): 34-37.

[4] Brilowski G, Wendler C. An evolutionary concept analysis of caring. J Advanced Nursing. 2005; 50(6): 641-650. PMid:15926969 https://doi.org/10.1111/j.1365-2648.2005.03449.x

[5] Udomluck S, Tonmukayakul O, Tiansawad S, et al. Development of Thai Nurses' Caring Behavior Scale. Pacific Rim Int J Nurs Res. 2010; 14(1): 32-44.

[6] Clarke P. From theory to practice: Caring science according to Watson and Brewer. Nursing Science Quarterly. 2009; 22: 339-345 PMid:19858513 https://doi.org/10.1177/08943184093447 69

[7] Watson J. Caring as the essence and science of Nursing and health care. O Mundo da Saude. 2009; 33(2): 143-149.

[8] Lukose A. Developing a Practice Model for Watson's Theory of Caring. Nursing Science Quarterly. 2011; 24(1): 27-30. PMid:21220572 https://doi.org/10.1177/0894318410389073

[9] Salimi S, Azimpour A. Determinants of Nurses' Caring Behaviors (DNCB): Preliminary Validation of a Scale. J Caring Sci. 2013; 2(4) 269-278. PMid:25276735

[10] Oskouie F, Rafii F, Nikravesh M. Major Determinants of caring behavior. Harward Health Policy Review. 2006; 7(1): 6-16.

[11] King D, Crisp J. Spirituality and health care education in family medicine residency programs. Fam Med. 2005; 37(6): 399-403. PMid:15933911

[12] Enns C, Gregory D. Lamentation and loss: expressions of caring by contemporary surgical nurses. J Adv Nurs. 2007; 58(4): 339-347. PMid:17425600 https://doi.org/10.1111/j.1365-2648.20 $07.04237 . \mathrm{x}$

[13] Modic MB, Siedlecki SL, Griffin MT, et al. Caring Behaviors: Perceptions of Acute-Care Nurses and Hospitalized Patients With Diabetes. International Journal for Human Caring. 2016; 20(3): 160-164. https://doi .org/10.20467/1091-5710-20.3.160

[14] Pai H, Eng C. The relationships among critical thinking disposition, caring behavior, and learning styles in student nurses. Open Journal of Nursing. 2013; 3(2): 249-256. https ://doi.org/10.4236/oj n. 2013.32034

[15] Joonbakhsh F, Pashaee S. Caring Behaviors Perceived by Nurses and Students in Critical Care Units in Tabriz University of Medical Sciences Affiliated Hospitals. Intl. Res. J. Appl. Basic. Sci. 2014; 8(4): 489-493.

[16] Meltzer L, Huckabay L. Critical Care Nurses' Perceptions of Futile Care and Its Effect on Burnout. American journal of critical care. 2004; 13(3): 202-8. PMid:15149054

[17] Balsdottir G, Jonsdottir H. The importance of nurses' caring behaviours as perceived by patients receiving care at an emergency department. Heart Lung: J Acute Crit Care. 2002; 31(1): 67-75. https://doi.org/10.1067/mhl.2002.119835

[18] Amendolair D. Caring behaviors and job satisfaction. Journal of Nursing Administration. 2012; 42(1): 34-39. PMid:22157380 https: //doi.org/10.1097/NNA.0b013e31823c18af

[19] Myhren H, Ekeberg Ø, Stokland O. Job satisfaction and burnout among intensive care unit nurses and physicians. Critical care research and practice. 2013; 2013: 1-6. PMid:24303211 https: //doi.org/10.1155/2013/786176

[20] McGrath M. The challenges of caring in a technological environment: critical care nurses' experiences. J Clin Nurs. 2008; 17(8): 1096-1104. PMid:18321273 https://doi.org/10.1111/j.1365-2702.20 $07.02050 . \mathrm{x}$

[21] Arthur D, Pang S, Wong T. The effect of technology on the caring attributes of an international sample of nurses. International Journal of Nursing Studies. 2001; 38: 37-43. https://doi.org/10.101 6/S0020-7489(00)00049-3

[22] O'Connell E, Landers M. The importance of critical care nurses' caring behaviours as perceived by nurses and relatives. Intensive and Critical Care Nursing. 2008; 24: 349-358. PMid:18499460 https://doi.org/10.1016/j.iccn.2008.04.002

[23] Tevington P. Mandatory Nurse-Patient Ratios. Professional Issues. 2011; 20(5): 265-268.

[24] Beeby J. Intensive care nurses' experiences of caring. Part 2. Intens Crit Care Nurs. 2000; 16: 151-63. PMid:10859624 https: //doi.org/10.1054/iccn.2000.1490

[25] Azizi-Fini I, Mousavi M, Mazroui-Sabdani A, et al. Correlation Between Nurses' Caring Behaviors and Patients' Satisfaction. Nurs Midwifery Stud. 2012; 1(1): 36-40. https://doi.org/10.5812/ nms. 7901

[26] Lange M, Thom B, Kline N. Assessing nurses' attitude toward death and caring for dying patients in a comprehensive cancer center. 
Oncology Nursing Forum. 2008; 35(6): 955-959. PMid: 18980927 https://doi.org/10.1188/08.0NF.955-959

[27] Ozawa M, Mizuno M, Evans D, et al. An investigation in to the nurses' behavior with regard to human caring in Japan. J Nurs Studies NCNJ. 2004; 3(1): 20-26.

[28] Noh C, Arthur D, Sohng K. Relationship between technological influences and caring attributes of Korean nurses. International Journal of Nursing Practice. 2002; 8: 247-256.

[29] Laerkner E, Egerod I, Hansen H. Nurses' experiences of caring for critically ill, non-sedated, mechanically ventilated patients in the Intensive Care Unit: a qualitative study. Intensive Crit Care Nurs. 2015; 31(4): 196-204. PMid:25743598 https://doi.org/10.1 016/j.iccn.2015.01.005

[30] Attia A, Abd-Elaziz W, Kandeel N. Critical Care Nurses' Perception of Barriers and Supportive Behaviors in End-of-Life Care. American Journal of Hospice and Palliative Medicine. 2012; 30 (3): 297-304. Mid:22743231

[31] Wilkin K, Slevin E. The meaning of caring to nurses: an investigation into the nature of caring work in an intensive care unit. Journal of Clinical Nursing. 2004; 13: 50-59. https://doi.org/10.1111/ j.1365-2702.2004.00814.x

[32] Cronin S, Harrison B. Importance of nurse caring behaviors as perceived by patients after myocardial infarction. Heart Lung. 1988; 17(4): 374-380. PMid:3391789

[33] Elbahnasawy H, Lawend J, Mohammed E. Application of Watson Caring Theory for Nurses in Pediatric Critical Care Unit. IOSR
Journal of Nursing and Health Science. 2016; 5(4): 56-67. https : //doi.org/10.9790/1959-0504045667

[34] Azma K, Goodarzi N, Tavakolian E, et al. The Difference Between Mu Suppression And Nurses' Empathy With The Difference Of Three Years Of Work Experience. Mater Sociomed. 2015; 27(6): 417-420. PMid:26889102 https://doi.org/10.5455/msm.2015.27.41 $7-420$

[35] Pajnkihar M, Štiglic G, Vrbnjak D. The concept of Watson's carative factors in nursing and their (dis) harmony with patient satisfaction. Peer J. 2017; 5: e2940. PMid:28194310 https ://doi .org/10.7 $717 /$ peerj. 2940

[36] Wenham T, Pittard A. Intensive care unit environment. Continuing Education in Anaesthesia Critical Care \& Pain. 2009; 9(6): 178-183. https://doi.org/10.1093/bjaceaccp/mkp036

[37] Han J, Wilber S. Altered mental status in older emergency department patients. Clinics in Geriatric Medicine. 2013; 29(1): 101-136. PMid:23177603 https://doi.org/10.1016/j.cger.2012.09 .005

[38] Poirier P, Sossong A. Oncology patients' and nurses' perceptions of caring. Canadian Oncology Nursing Journal. 2010; 20(2): 62-65. https://doi.org/10.5737/1181912x2026265

[39] Shen H, Chiu H, Lee H, et al. Hospital environment, nurse-physician relationships and quality of care: questionnaire survey. J Adv Nurs. 2011; 67(2): 349-58. PMid:21044136 https://doi.org/10.111 $1 / j .1365-2648.2010 .05502 . x$ 